\title{
Validation of the 2009 TNM Version in a Large Multi-Institutional Cohort of Patients Treated for Renal Cell Carcinoma: Are Further Improvements Needed?
}

\author{
Giacomo Novara ${ }^{a}$, Vincenzo Ficarra ${ }^{a, *}$, Alessandro Antonelli ${ }^{b}$, Walter Artibani $^{a}$, \\ Roberto Bertini $^{c}$, Marco Carini $^{d}$, Sergio Cosciani Cunico ${ }^{b}$, Ciro Imbimbo $^{e}$, Nicola Longo $^{e}$, \\ Guido Martignoni $^{f}$, Giuseppe Martorana ${ }^{g}$, Andrea Minervini ${ }^{d}$, Vincenzo Mirone $^{e}$, \\ Francesco Montorsi $^{c}$, Roberto Schiavina ${ }^{g}$, Claudio Simeone $^{b}$, Sergio Serni $^{d}{ }^{\text {, Alchiede Simonato }}{ }^{h}$, \\ Salvatore Siracusano ${ }^{i}$, Alessandro Volpe ${ }^{j}$, Giorgio Carmignani $^{h}$ \\ members of the SATURN Project-LUNA Foundation ${ }^{1}$
}

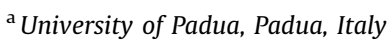

${ }^{\mathrm{b}}$ University of Brescia, Brescia, Italy

${ }^{\mathrm{c}}$ Vita-Salute University San Raffaele, Milan, Italy

${ }^{\mathrm{d}}$ University of Florence, Florence, Italy

e University Federico II, Naples, Italy

${ }^{\mathrm{f}}$ University of Verona, Verona, Italy

${ }^{\mathrm{g}}$ University of Bologna, Bologna, Italy

${ }^{\mathrm{h}}$ University of Genova, Genova, Italy

${ }^{\mathrm{i}}$ University of Trieste, Trieste, Italy

${ }^{\mathrm{j}}$ University of Eastern Piedmont, Novara, Italy
}

\section{Article info}

\section{Article history:}

Accepted July 9, 2010

Published online ahead of print on July 23, 2010

\section{Keywords:}

Kidney neoplasm

Renal cell carcinoma

TNM

Nephrectomy

\begin{abstract}
Background: A new edition of the TNM was recently released that includes modifications for the staging system of kidney cancers. Specifically, T2 cancers were subclassified into T2a and T2b ( $\leq 10 \mathrm{~cm}$ vs $>10 \mathrm{~cm}$ ), tumors with renal vein involvement or perinephric fat involvement were classified as T3a cancers, and those with adrenal involvement were classified as T4 cancers.

Objective: Our aim was to validate the recently released edition of the TNM staging system for primary tumor classification in kidney cancer.

Design, setting, and participants: Our multicenter retrospective study consisted of 5339 patients treated in 16 academic Italian centers.

Intervention: Patients underwent either radical or partial nephrectomy.

Measurements: Univariable and multivariable Cox regression models addressed cancer-specific survival (CSS) after surgery.

Results and limitations: In the study, 1897 patients (35.5\%) were classified as pT1a, $1453(27 \%)$ as pT1b, 437 (8\%) as pT2a, 153 (3\%) as pT2b, 1059 (20\%) as pT3a, 117

\footnotetext{
${ }^{1}$ See appendix.

* Corresponding author. Department of Oncological and Surgical Sciences, Urology Clinic, University of Padua, Monoblocco Ospedaliero, IV floor, Via Giustiniani 2, 35100 - Padua, Italy. Tel. +39 0498212720; Fax: +39 0498218757.

E-mail address: vincenzo.ficarra@unipd.it (V. Ficarra).
} 
(2\%) as pT3b, $26(0.5 \%)$ as pT3c, and $197(4 \%)$ as pT4. At a median follow-up of 42 mo, $786(15 \%)$ had died of disease. In univariable analysis, patients with pT2b and pT3a tumors had similar CSS, as did patients with pT3c and pT4 tumors. Moreover, both pT3a and pT3b stages included patients with heterogeneous outcomes. In multivariable analysis, the novel classification of the primary tumor was a powerful independent predictor of CSS ( $p$ for trend $<0.0001$ ). However, the substratification of pT1 tumors did not retain an independent predictive role. The major limitations of the study are retrospective design, lack of central pathologic review, and the small number of patients included in some substages.

Conclusions: The recently released seventh edition of the primary tumor staging system for kidney tumors is a powerful predictor of CSS. However, some of the substages identified by the classification have overlapping prognoses, and other substages include patients with heterogeneous outcomes. The few modifications included in this edition may have not resolved the most critical issues in the previous version.

(C) 2010 European Association of Urology. Published by Elsevier B.V. All rights reserved.

\section{Introduction}

TNM classification is the globally accepted method of describing the anatomic extent of cancer. In kidney tumors, the outcome stratification proposed in the sixth edition of the TNM, published in 2002, was validated in several studies [1-3]. However, some studies suggested that patients with localized cancers could be better dichotomized around a tumor diameter of 5-6 cm [4-7] and that T3a and pT3b stages were heterogeneous [8]. Consequently, several proposals for further updates were implemented, both for localized [9,10] and locally advanced [11-17] disease.

Very recently, the Union Internationale Contre le Cancer (UICC) and the American Joint Committee on Cancer (AJCC) released the seventh edition of the staging system, which took effect on January 1, 2010. In this latest update, some modifications were made to the staging system for kidney tumors. In comparison with the sixth edition of TNM, T2 cancers were subclassified into two subgroups based on a tumor size cut-off point of $10 \mathrm{~cm}$ (T2a $\leq 10 \mathrm{~cm}$ vs T2b $>10 \mathrm{~cm}$ ). Moreover, tumors with renal vein involvement or perinephric fat involvement were classified as T3a, whereas those with adrenal involvement were classified as T4 cancers. All the other categories were unchanged [18].

The purpose of the present study was to validate the recently released seventh edition of the TNM staging system for primary tumor classification in kidney tumors in a multicenter series of patients with renal cell carcinoma (RCC) treated with radical nephrectomy (RN) or partial nephrectomy (PN) in 16 academic centers in Italy.

\section{Patients and methods}

The Surveillance and Treatment Update Renal Neoplasms (SATURN) project was promoted by LUNA, the Leading Urological No-Profit Foundation for Advanced Research of the Società Italiana di Urologia (ie, the Italian Society of Urology). A total of 16 academic centers in Italy provided data. The database comprised 5893 patients who underwent RN or PN between 1995 and 2007 because of a suspicion of kidney cancer. The patients with benign histology $(n=430)$, those lacking histologic subtypes of the tumor $(n=85)$, and those where the concomitant presence of some adverse pathologic features was not reported $(n=39)$ were excluded from the study. The 5339 remaining patients were the subjects of the present analysis.

The mode of presentation was distinguished according to the Patard classification [19]. Clinical staging included at least abdominal computed tomography (CT) scans and chest X-rays. Bone scans and brain CT scans were obtained only when indicated by signs and symptoms.

Surgery was performed by several surgeons according to the standard criteria for RN (ie, extrafascial dissection of the kidney). The hilar and regional lymph nodes adjacent to the ipsilateral great vessel generally were resected, along with enlarged lymph nodes if they were abnormal on preoperative CT scans or palpable intraoperatively. Extended lymphadenectomy was routinely performed in a few centers. In patients with a contralateral normal kidney, elective PN had been routinely indicated in the presence of single peripheral tumors $\leq 4 \mathrm{~cm}$, although some referral centers also performed elective PN in the case of larger tumors.

\subsection{Pathologic evaluation}

All surgical specimens were processed according to standard pathologic procedures at each institution. Tumor stage was reassigned according to the recently released seventh edition of the AJCC-UICC TNM classification. Specifically, T2 cancers were subclassified into two subgroups based on a tumor size cut-off point of $10 \mathrm{~cm}$ (T2a $\leq 10 \mathrm{~cm}$ vs T2b $>10 \mathrm{~cm}$ ), tumors with renal vein involvement or perinephric fat involvement were classified as T3a, whereas those with adrenal involvement were classified as T4 cancers. Classification of T1 tumors, as well as of those with vena cava thrombus and Gerota fascia invasion, was unchanged [18].

The Heidelberg and Fuhrman classifications were used to assign histologic type and nuclear grade, respectively [20,21]. No central pathologic slide review was performed.

\subsection{Follow-up regimen}

Patients were generally observed every 3-4 mo for the first year after surgery, every 6 mo from the second through the fifth years, and annually thereafter. Follow-up consisted of a history, a physical examination, routine blood work and serum chemistry studies, chest radiography, and radiographic evaluation of the contralateral or remnant kidney. Elective bone scan, chest CT, and magnetic resonance imaging were performed when clinically indicated.

Cause of death was determined by the treating physicians, by chart review corroborated by death certificates, or by death certificates alone. 


\subsection{Statistical analysis}

Continuous variables were reported as median value and interquartile ranges (IQRs). The Kaplan-Meier method was used to calculate survival functions, and differences were assessed with the log-rank statistic. Univariable and multivariable Cox regression models addressed time to cancer-specific mortality after surgery. Patients alive and disease free were censored. Statistical significance in this study was set as $p<0.05$. All reported $p$ values are two sided. Analyses were performed with SPSS v.16.0 (SPSS Inc, Chicago, IL, USA) by one of the authors (GN).

\section{Results}

Table 1 summarizes the clinical and pathologic features of the 5339 analyzed patients. Based on the novel TNM staging system, 1897 of the patients (35.5\%) were classified as pT1a, $1453(27 \%)$ as pT1b, $437(8 \%)$ as pT2a, 153 (3\%) as pT2b, $1059(20 \%)$ as pT3a, $117(2 \%)$ as pT3b, $26(0.5 \%)$ as pT3c, and $197(4 \%)$ as pT4.

At a median follow-up of 42 mo (IQR: 24-75 mo), 3949 patients (74\%) were alive and disease free, 786 (15\%) had died of disease, and 335 (6\%) had died of other causes. Median follow-up of the 3987 living patients was 48 mo (IQR: 25-84 mo). The overall 5- and 10-yr cancer-specific survival (CSS) estimates were $83.2 \%$ (standard error [SE]: $0.6 \%$ ) and $76.6 \%$ (SE: 0.9\%), respectively.

According to the 2009 TNM staging system, 5-yr CSS was 94.9\% (SE: 0.6\%) in pT1a, 92.6\% (SE: 0.8\%) in pT1b, 85.4\% (SE: $1.9 \%$ ) in pT2a, $70 \%$ (SE: $4.1 \%$ ) in pT2b, $64.7 \%$ (SE: $1.8 \%$ ) in pT3a, 54.7\% (SE: $5.9 \%$ ) in pT3b, $17.9 \%$ (SE: $10.1 \%$ ) in pT3c, and $27.1 \%$ (SE: $4.0 \%$ ) in pT4 (pooled over strata $p<0.00001$ ) (Fig. 1). All the pairwise survival differences among the different pT stages were statistically significant with the exception of those observed between pT2b and pT3a cancers (log-rank pairwise $p=0.34$ ) and between pT3c and pT4 cancers (pairwise $p=0.26$ ). Considering only the 4848 cases with N0/NxM0 disease, the survival differences between pT1a and pT1b, pT2b and pT3a, pT3a and pT3b, and pT3c and pT4 were not statistically significant (pairwise $p$ values $>0.05$; data not extensively shown).

The pT3a subcategory was composed of 503 cases (47\%) with perinephric fat invasion only, 401 (38\%) with renal vein invasion only, and 155 (15\%) with concomitant perinephric fat and renal vein invasion. Patients with isolated perinephric fat and renal vein invasion had similar outcomes (pairwise $p=0.05$ ), but the patients with the two concomitant features had significantly lower CSS (pairwise $p$ values $<0.0001$ ) (Fig. 2). Considering only the 866 cases with pT3aNOM0 RCC, patients with renal vein invasion had the highest CSS, followed by those with only perirenal fat invasion and by those with the two concomitant features, with all the survival differences being statistically significant (pairwise $p$ values $<0.045$; data not extensively shown).

The pT3b subcategory included 69 cases (59\%) with infradiaphragmatic vena caval thrombus only, and 48 cases (41\%) with concomitant infradiaphragmatic vena caval thrombus and perirenal fat invasion. Those patients with the two concomitant features had significantly lower CSS
Table 1 - Clinical and pathologic features of the 5339 analyzed patients

\begin{tabular}{|c|c|}
\hline Variables & \\
\hline Age, yr, median (IQR) & $63(54-71)$ \\
\hline \multicolumn{2}{|l|}{ Gender, No. (\%) } \\
\hline Male & $3538(66)$ \\
\hline Female & $1801(34)$ \\
\hline \multicolumn{2}{|l|}{ Mode of presentation, No. (\%) } \\
\hline Incidental & $3335(62)$ \\
\hline Local symptoms & $1438(27)$ \\
\hline Systemic symptoms & $260(5)$ \\
\hline \multicolumn{2}{|l|}{ Type of surgery, No. (\%) } \\
\hline Radical nephrectomy & $3799(71)$ \\
\hline Elective partial nephrectomy & $1311(25)$ \\
\hline Imperative partial nephrectomy & $229(4)$ \\
\hline \multicolumn{2}{|l|}{ Histologic subtype, No. (\%) } \\
\hline Clear cell & $4334(81)$ \\
\hline Papillary & $577(11)$ \\
\hline Chromophobe & $291(6)$ \\
\hline Collecting duct & $47(1)$ \\
\hline Unclassified & $90(2)$ \\
\hline Pathologic tumor size, median (IQR) & $5(3.5-7)$ \\
\hline \multicolumn{2}{|l|}{ Pathologic T stage (TNM 2002), No. (\%) } \\
\hline T1a & $1897(35.5)$ \\
\hline T1b & $1453(27)$ \\
\hline $\mathrm{T} 2$ & $590(11)$ \\
\hline T3a & $547(10)$ \\
\hline $\mathrm{T} 3 \mathrm{~b}$ & $710(13)$ \\
\hline T3c & $26(0.5)$ \\
\hline $\mathrm{T} 4$ & $116(2)$ \\
\hline \multicolumn{2}{|l|}{ Pathologic T stage, TNM 2009, No. (\%) } \\
\hline $\mathrm{T} 1 \mathrm{a}$ & $1897(35.5)$ \\
\hline $\mathrm{T} 1 \mathrm{~b}$ & $1453(27)$ \\
\hline $\mathrm{T} 2 \mathrm{a}$ & $437(8)$ \\
\hline $\mathrm{T} 2 \mathrm{~b}$ & $153(3)$ \\
\hline T3a & $1059(20)$ \\
\hline T3b & $117(2)$ \\
\hline T3c & $26(0.5)$ \\
\hline $\mathrm{T} 4$ & $197(4)$ \\
\hline \multicolumn{2}{|l|}{ Pathologic N stage, No. (\%) } \\
\hline $\mathrm{Nx}$ & $3062(57)$ \\
\hline No & $2034(38)$ \\
\hline N1 & $116(2)$ \\
\hline N2 & $127(2)$ \\
\hline \multicolumn{2}{|l|}{ M stage, No. (\%) } \\
\hline M0 & $5016(94)$ \\
\hline M1 & $323(6)$ \\
\hline \multicolumn{2}{|l|}{ Fuhrman nuclear grade, No. (\%) } \\
\hline G1 & $621(11)$ \\
\hline G2 & $2783(50)$ \\
\hline G3 & $1399(25)$ \\
\hline G4 & $408(7)$ \\
\hline $\begin{array}{l}\mathrm{IQR}=\text { interquartile range. } \\
\text { Missing in } 306 \text { cases (6\%). } \\
\text { Missing in } 395 \text { cases ( } 7 \%) .\end{array}$ & \\
\hline
\end{tabular}

compared with those with thrombus only $(p=0.0007)$ (Fig. 3). Similar statistics were obtained limiting the analysis to the 84 pT3bNOMO cases ( $p=0.005$ ).

The pT3c subcategory was composed of 16 patients (61\%) with supradiaphragmatic vena caval thrombus only, and 10 patients (39\%) with concomitant supradiaphragmatic vena caval thrombus and perirenal fat invasion. The two subgroups of pT3c patients had overlapping CSS 


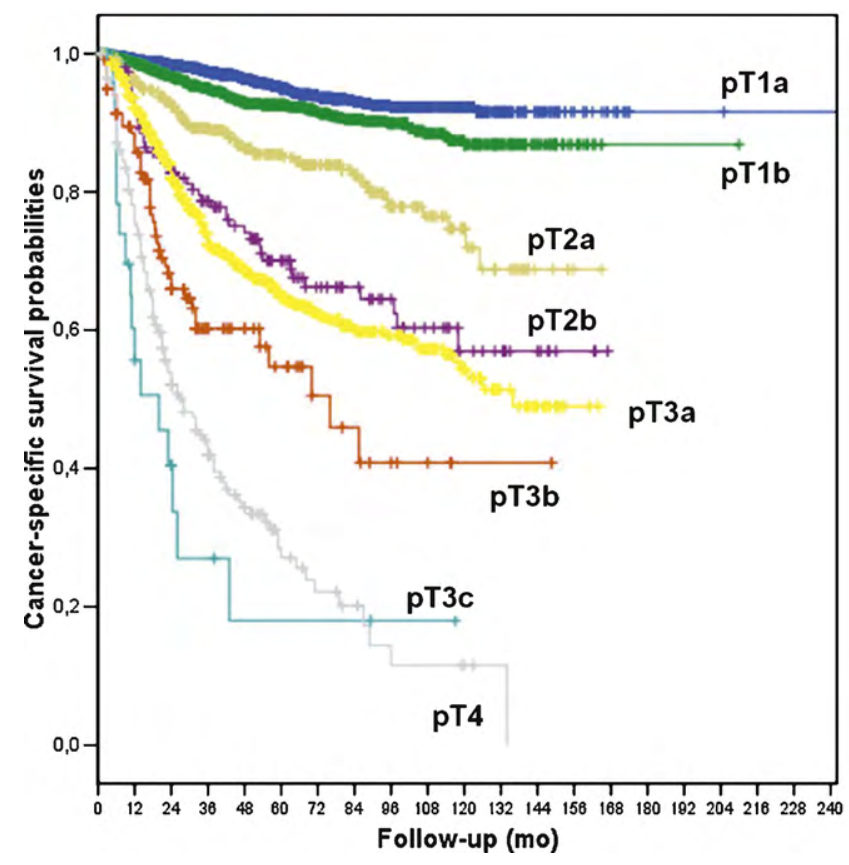

Fig. 1 - Cancer-specific survival (CSS) probability according to the 2009 TNM staging system (log rank pooled over strata $p<0.0001)$. Five-year CSS was $94.9 \%$ in pT1a (blue curve), $92.6 \%$ in pT1b (green curve), $85.4 \%$ in pT2a (gray curve), 70\% in pT2b (violet curve), $64.7 \%$ in pT3a (yellow curve), 54.7 in pT3b (red curve), 17.9 in pT3c (light blue curve), and $27.1 \%$ in pT4 (light gray curve). All the pairwise survival differences among the different pT stages were statistically significant with the exception of those observed between pT2b and pT3a cancers (log-rank pairwise $p=0.34$ ) and between $\mathrm{pT} 3 \mathrm{c}$ and $\mathrm{pT} 4$ cancers $(\log$-rank pairwise $p=0.26)$.

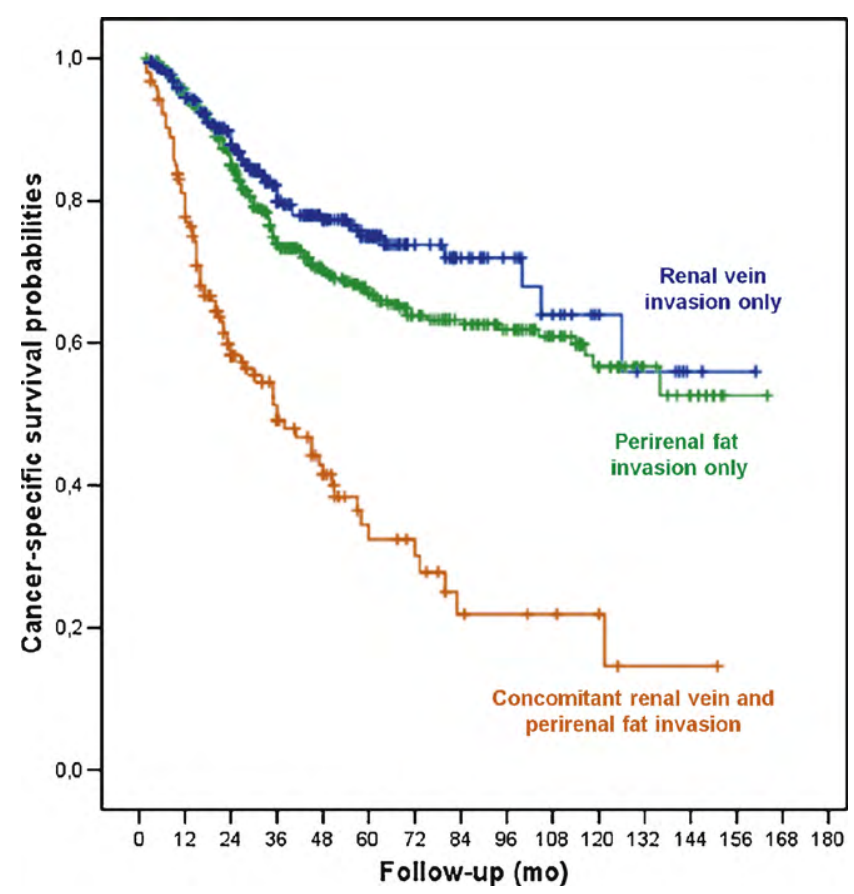

Fig. 2 - Cancer-specific survival (CSS) probability within the pT3a subcategory (log-rank pooled over strata $p<0.0001)$. Five-year CSS was $75 \%$ in patients with renal vein invasion only (blue curve), $66.9 \%$ in patients with perirenal fat invasion only (green curve), and $32.4 \%$ in patients with the two concomitant features (red curve). Renal vein invasion only versus perirenal fat invasion only: log-rank pairwise $\boldsymbol{p}=\mathbf{0 . 0 5}$. Concomitant renal vein and perirenal fat invasion versus each individual features: log-rank pairwise $p<0.0001$.

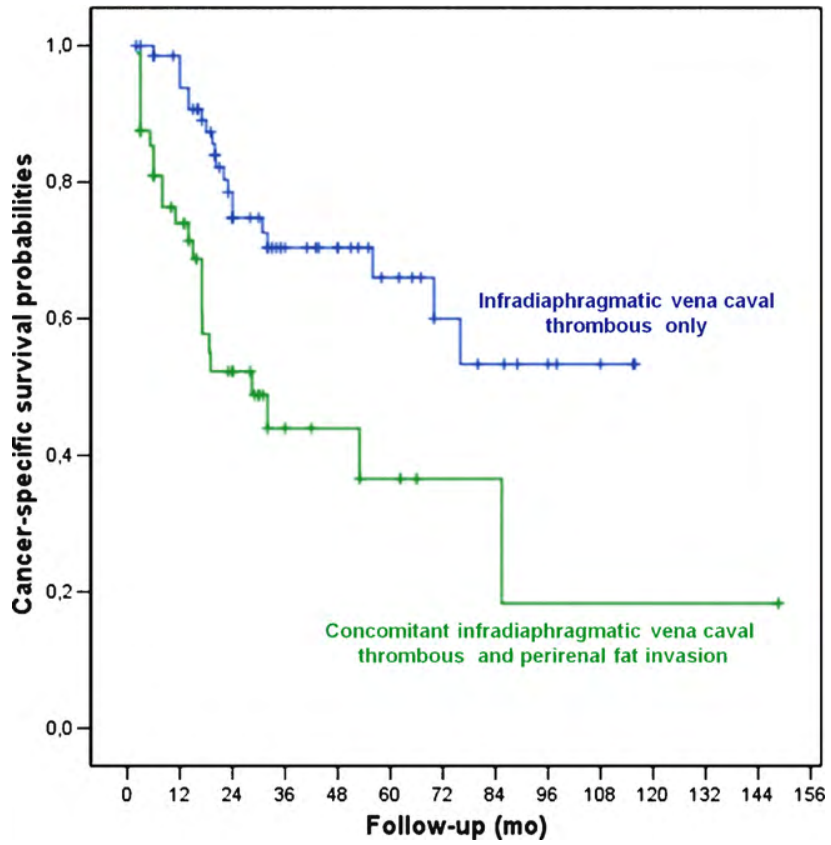

Fig. 3 - Cancer-specific survival (CSS) probability within the pT3b subcategory. Five-year CSS was $65.9 \%$ in patients with infradiaphragmatic vena caval thrombus only (blue curve) and $36.5 \%$ in patients with concomitant invasion of the perirenal fat (green curve). Log-rank pooled over strata $\boldsymbol{p}=\mathbf{0 . 0 0 0 7}$.

( $p=0.33$ ) (Fig. 4). Similar figures were obtained limiting the analysis to the 12 pT3cNOM0 cases ( $p=0.135$ ).

Evaluating the prognostic role of the proximal extension of tumor thrombus with renal or caval veins, all the CSS differences among the 628 patients with renal vein, 146 with infradiaphragmatic, and 27 with supradiaphragmatic vena caval thrombus were statistically significant ( $p$ values $<0.009$ ). However, considering only the 405 patients with NOMO disease and isolated tumor thrombus in the absence of other adverse pathologic features, the CSS of those with renal vein thrombosis and infradiaphragmatic vena caval thrombus was similar $(p=0.267)$. Patients with infradiaphragmatic or supradiaphragmatic vena caval thrombus had a similar prognosis $(p=0.067)$.

The pT4 subcategory included 68 cases (29\%) with tumor extending beyond the Gerota fascia, 81 cases (41\%) with adrenal gland invasion, and 48 cases (24\%) with the two concomitant features. The three subgroups of pT4 patients had similar outcomes $(p=0.32)$ (Fig. 5). Similar figures were obtained limiting the analysis to the 97 pT4NOM0 cases ( $p$ values $>0.05$; data not extensively shown). Table 2 summarizes the data of univariable and multivariable analyses for CSS.

On multivariable Cox regression analyses, the $\mathrm{T}$ stage according to the 2009 staging system was an independent predictor of CSS ( $p$ for trend $<0.0001$ ), once adjusted for the effect of all the other covariates. Notably, the substratification of T1 tumors was not an independent predictor of survival in multivariable analysis (hazard ratio [HR]: 1.1; $p=0.70$ ). Limiting the analysis to NOMO cases, the $2009 \mathrm{~T}$ stage retained an independent predictor role ( $p$ for trend 


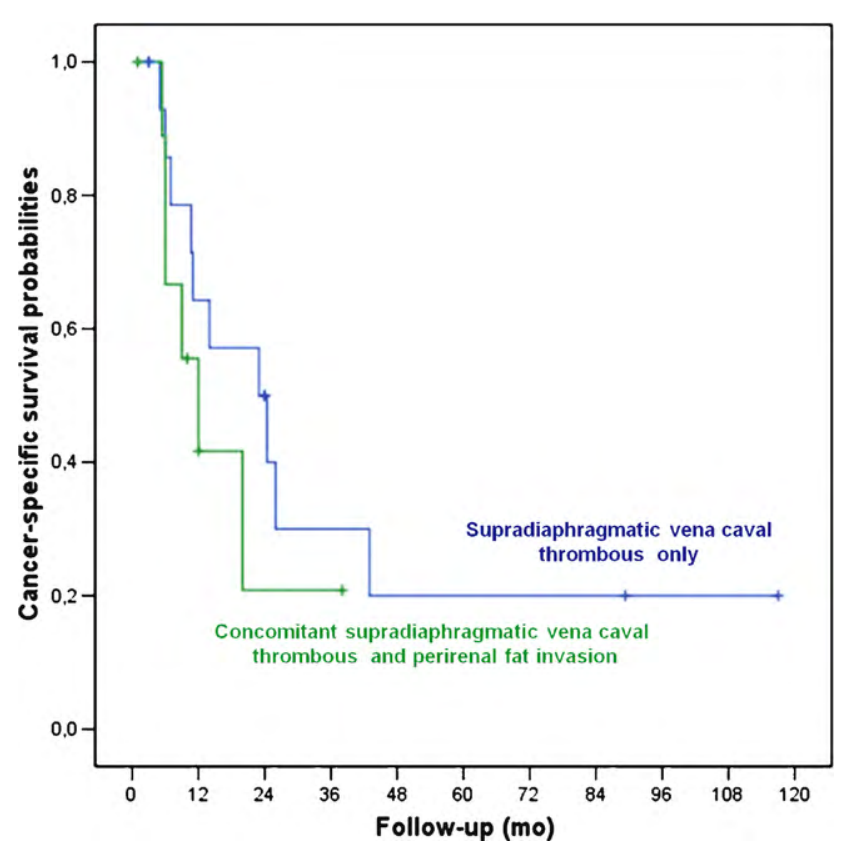

Fig. 4 - Cancer-specific survival (CSS) probability within the pT3c subcategory. Three-year CSS was $\mathbf{3 0} \%$ in patients with supradiaphragmatic vena caval thrombus only (blue curve) and $20 \%$ in patients with concomitant invasion of the perirenal fat (green curve). Log-rank pooled over strata $\boldsymbol{p}=\mathbf{0 . 3 3}$.

$<0.0001$ ). However, pT1b (HR: 0.9; $p=0.463$ ) and pT2a (HR: $1.5 ; p=0.77$ ) were not statistically significantly different from the reference pT1a group (data not extensively shown).

\section{Discussion}

We have reported what is to our knowledge the first attempt to validate the recently released seventh edition of the TNM staging system for RCC. In the present series, the novel classification of the primary tumor was a powerful independent predictor of CSS. However, some of the substages identified by the classification had overlapping prognoses (pT2b and pT3a; pT3c and pT4 RCC), whereas both pT3a and pT3b stages included patients with heterogeneous outcomes. Lastly, in multivariable analysis, the substratification of pT1 RCC into pT1a and pT1b did not retain an independent predictive role for CSS.

The TNM staging system should effectively communicate critical tumor characteristics, aid the clinician in the appropriate selection of therapeutic options, stratify the patient's risk of cancer progression or cancer death, allow the evaluation of treatment results, make data comparison from different centers easy, and determine the selection criteria for clinical trials [22]. To accomplish all these purposes, in 2002, the UICC introduced a structured process for regular updates of the TNM classification system [22]. Applying such a process, the seventh edition of the staging system for RCC introduced a subclassification of T2 into two subgroups based on a tumor size cut-off point of $10 \mathrm{~cm}$ (T2a $\leq 10 \mathrm{~cm}$ vs $\mathrm{T} 2 \mathrm{~b}>10 \mathrm{~cm}$ ) and reclassified direct adrenal involvement as T4 cancers [18].

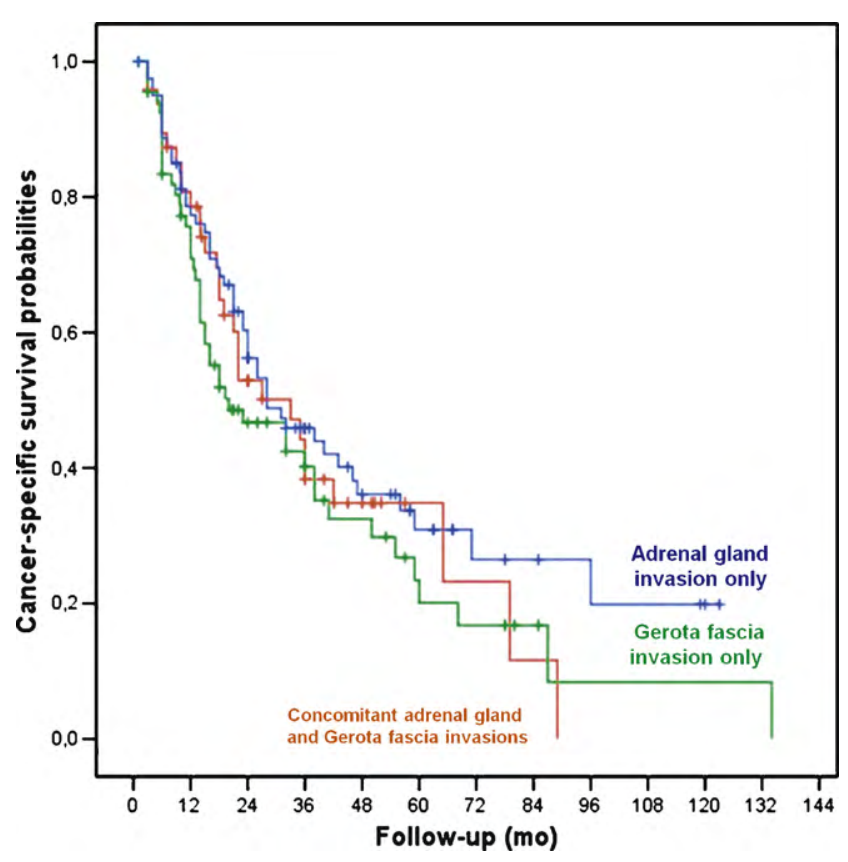

Fig. 5 - Cancer-specific survival (CSS) probability within the pT4 subcategory $(\log -$ rank pooled over strata $p=0.32$ ). Five-year CSS was $30.9 \%$ in patients with adrenal gland invasion only (blue curve), $20 \%$ in patients with invasion of the Gerota fascia (green curve), and $34.8 \%$ in patients with the two concomitant features (red curve). Gerota fascia invasion only versus adrenal gland invasion only: log-rank pairwise $p=0.14$. Concomitant Gerota fascia and adrenal gland invasion versus adrenal gland invasion only: log-rank pairwise $p=0.47$. Concomitant Gerota fascia and adrenal gland invasion versus Gerota fascia invasion only: $\log$ rank pairwise $\boldsymbol{p}=\mathbf{0 . 5 3}$.

Regarding localized RCC, the T2 subclassification was based on a study from the Mayo Clinic in which the $10-\mathrm{cm}$ break point was able to stratify $\mathrm{T} 2$ patients into two substages with statistically different survival probabilities, both better than those observed in pT3a cases [10]. In the present analysis, the CSS probabilities of $\mathrm{pT} 2 \mathrm{~b}$ patients were similar to those of the new pT3a substage. That result might be due to the small number of patients included in these subgroups (only 3\%), as well as the overall improvement of the outcomes of the pT3a patients after removal of cases with direct adrenal involvement, reclassified as pT4 in the new TNM. On the whole, the modification of RCC primary tumor classification wound up splitting localized cancers into four subgroups (T1a vs T1b vs T2a vs T2b) that were numerically imbalanced, with most of the patients still classified as T1. Moreover, in terms of clinical staging, the subclassification of $\mathrm{T} 1$ cancers is losing its main clinical relevance because the indication for elective PN in tumors has been extended to tumors $>4 \mathrm{~cm}[23,24]$. Consequently, a staging system based on a cut-off point in the range of 5-6 cm might be more suitable from a clinical point of view to indicate those patients suitable for PN as well as, according to the available data, to dichotomize the cancerrelated outcome of localized cancers [4-7,9].

With regard to the updates in the staging of locally advanced RCC, the choice to move direct adrenal invasion into the pT4 stage was driven by several studies, all of which demonstrated that tumors with adrenal invasion had the 
Table 2 - Univariable and multivariable Cox regression analyses of TNM staging system for prediction of cancer-specific mortality in 5339 patients (786 cancer-specific deaths)

\begin{tabular}{|c|c|c|c|c|c|c|}
\hline \multirow[b]{2}{*}{ Parameter } & \multicolumn{3}{|c|}{ Univariable analysis } & \multicolumn{3}{|c|}{ Multivariable analysis } \\
\hline & HR & $95 \% \mathrm{CI}$ & $p$ value & $\mathrm{HR}$ & $95 \% \mathrm{CI}$ & $p$ value \\
\hline Age, continuous & 1.02 & $1.01-1.02$ & $<0.001$ & 1.01 & $1-1.02$ & 0.002 \\
\hline Gender & & & 0.016 & & & $<0.001$ \\
\hline Male & 1 & Reference & - & 1 & Reference & - \\
\hline Female & 0.8 & $0.7-0.9$ & - & 0.7 & $0.6-0.9$ & - \\
\hline Mode of presentation & & & $<0.001$ & & & $<0.001$ \\
\hline Incidental & 1 & Reference & - & 1 & Reference & - \\
\hline Local symptoms & 2.6 & $2.3-3.1$ & $<0.001$ & 1.4 & $1.2-1.7$ & $<0.001$ \\
\hline Systemic symptoms & 6.9 & $5.6-8.6$ & $<0.001$ & 2.0 & $1.5-2.5$ & $<0.001$ \\
\hline Type of surgery & & & $<0.001$ & & & 0.050 \\
\hline Radical nephrectomy & 1 & Reference & - & 1 & Reference & - \\
\hline Elective partial nephrectomy & 0.2 & $0.1-0.3$ & $<0.001$ & 0.6 & $0.5-0.9$ & 0.019 \\
\hline Imperative partial nephrectomy & 0.6 & $0.4-0.9$ & 0.009 & 1.1 & $0.7-1.7$ & 0.655 \\
\hline Histologic subtype & & & $<0.001$ & & & $<0.001$ \\
\hline Clear cell & 1 & Reference & - & 1 & Reference & - \\
\hline Papillary & 0.8 & $0.6-0.9$ & 0.032 & 0.7 & $0.5-0.9$ & 0.024 \\
\hline Chromophobe & 0.4 & $0.3-0.7$ & $<0.001$ & 0.6 & $0.4-0.9$ & 0.040 \\
\hline Collecting duct & 4.1 & $2.6-6.5$ & $<0.001$ & 2.4 & $1.4-4.0$ & 0.001 \\
\hline Unclassified & 2.9 & $2.0-4.2$ & $<0.001$ & 1.7 & $1.2-2.5$ & 0.009 \\
\hline Pathologic tumor size, continuous & 1.2 & $1.1-1.2$ & $<0.001$ & 1.03 & $1.0-1.06$ & 0.016 \\
\hline Pathologic T stage & & & $<0.001$ & & & $<0.001$ \\
\hline T1a & 1 & Reference & - & 1 & Reference & - \\
\hline $\mathrm{T} 1 \mathrm{~b}$ & 1.6 & $1.2-2.2$ & 0.001 & 1.1 & $0.8-1.5$ & 0.700 \\
\hline $\mathrm{T} 2 \mathrm{a}$ & 3.6 & $2.6-4.9$ & $<0.001$ & 1.8 & $1.2-2.6$ & 0.002 \\
\hline $\mathrm{T} 2 \mathrm{~b}$ & 7.2 & $5-10.3$ & $<0.001$ & 2.6 & $1.6-4.2$ & $<0.001$ \\
\hline T3a & 8.4 & $6.6-10.8$ & $<0.001$ & 2.8 & $2.1-3.9$ & $<0.001$ \\
\hline $\mathrm{T} 3 \mathrm{~b}$ & 14.2 & $9.9-20.6$ & $<0.001$ & 3.8 & $2.5-5.9$ & $<0.001$ \\
\hline $\mathrm{T} 3 \mathrm{c}$ & 36.7 & $21.5-63.2$ & $<0.001$ & 6.4 & $3.3-12.7$ & $<0.001$ \\
\hline $\mathrm{T} 4$ & 26.6 & $20.0-35.2$ & $<0.001$ & 3.1 & $2.1-4.7$ & $<0.001$ \\
\hline Pathologic N stage & & & $<0.001$ & & & $<0.001$ \\
\hline NO & 1 & Reference & - & 1 & Reference & - \\
\hline $\mathrm{Nx}$ & 0.6 & $0.5-0.7$ & $<0.001$ & 0.9 & $0.7-1.1$ & 0.293 \\
\hline $\mathrm{N} 1$ & 6.9 & $5.3-8.9$ & $<0.001$ & 2.2 & $1.6-2.9$ & $<0.001$ \\
\hline N2 & 8.7 & $6.9-10.9$ & $<0.001$ & 2.2 & $1.7-2.9$ & $<0.001$ \\
\hline M stage & & & $<0.001$ & & & $<0.001$ \\
\hline M0 & 1 & Reference & - & 1 & Reference & - \\
\hline $\mathrm{M}+$ & 12.7 & $10.9-14.8$ & - & 4.1 & $3.4-4.9$ & - \\
\hline Fuhrman nuclear grade & & & $<0.001$ & & & $<0.001$ \\
\hline G1 & 1 & Reference & - & 1 & Reference & - \\
\hline G2 & 2.0 & $1.4-3.0$ & $<0.001$ & 1.6 & $1.01-2.4$ & 0.047 \\
\hline G3 & 6.4 & $4.3-9.5$ & $<0.001$ & 2.7 & $1.7-4.1$ & $<0.001$ \\
\hline G4 & 18.0 & $12-26.9$ & $<0.001$ & 3.4 & $2.1-5.4$ & $<0.001$ \\
\hline
\end{tabular}

same aggressive clinical behavior of those extending beyond the Gerota fascia [12-14,16,17]. However, the pT3a and pT3b stages both included patients with different CSS (ie, those presenting concomitant unfavorable features). The opportunity to stratify the outcome of patients with locally advanced RCC taking in account the concomitant presence of multiple concomitant pathologic features had been proposed in three previous studies, all of which aimed at improving the primary tumor classification of locally advanced RCC [12-14]. Specifically, Thompson et al had reported on about 700 patients treated at the Mayo Clinic, proposing to distinguish locally advanced RCC into five subgroups (pT3a, renal vein thrombosis only; pT3b, fat invasion only; pT3c, renal vein thrombosis and perirenal fat infiltration or subdiaphragmatic vena cava thrombosis only; pT3d, subdiaphragmatic vena cava thrombosis with perirenal fat infiltration or supradiaphragmatic inferior vena cava thrombosis; and pT4, extension beyond the Gerota fascia or ipsilateral adrenal invasion) [12]. However, although all components of the proposed reclassification were statistically significantly different from the reference group consisting of patients with renal vein thrombosis only after adjusting for $\mathrm{N}$ and $\mathrm{M}$ stages, the survival probabilities of all the subgroups were clearly overlapping in Thompson's paper. Similarly, Ficarra et al evaluated 227 patients treated at two academic Italian centers, proposing 
to distinguish pT3a (perirenal fat invasion or renal vein thrombosis or thrombosis within the vena cava below the diaphragm), pT3b (renal vein thrombosis or thrombosis within the vena cava below the diaphragm associated with perirenal fat invasion), and pT4 (adrenal gland invasion or Gerota fascia invasion or thrombosis within the vena cava above the diaphragm) [13]. That proposal was further updated in a larger analysis involving about 2000 patients with pT3-pT4 RCC treated at 12 European centers. The data from that analysis suggested the possibility of stratifying locally advanced RCC as follows: pT3a, renal vein or infradiaphragmatic vena caval thrombosis, or perirenal fat invasion; pT3b, ipsilateral adrenal direct invasion or venous thrombosis plus perirenal fat invasion; pT4, venous thrombosis and ipsilateral adrenal direct invasion, supradiaphragmatic vena caval thrombosis or tumors extending beyond Gerota fascia [14]. However, none of these proposals for reclassification of locally advanced RCC were included in the new staging system, and the prognostic role of the concomitant presence of adverse pathologic features (eg, perirenal fat involvement and extent of tumor thrombosis) was not taken in account.

There are several limitations to our study. First and foremost are those inherent to any retrospective analysis. In addition, the population in this study underwent surgery in multiple centers, and specimens were evaluated by multiple pathologists without slide review. However, all surgeons operated at selected centers with significant experience in RCC management, which might increase the external validity of the data as compared with the singlecenter, single-surgeon setting. Similarly, although it may be preferable for a single pathologist specialized in genitourinary pathology to review each specimen, the present study reflects a real-world scenario. Moreover, although the series was very large, the number of pT2b, pT3b, pT3c, and pT4 cases was quite low, which might have resulted in some underpowered statistical analyses. This low number partially reflects the stage's distribution of RCC at surgery but is significantly affected by the excessive tendency to substratify in the current TNM staging system, which includes four substages for localized RCC and four for locally advanced RCC. Finally, most of the patients who had a recurrence of disease in the present cohort did not have access to targeted therapies and were treated before the development of tyrosine kinase and mammalian target of rapamycin inhibitors.

\section{Conclusions}

In the present series, the recently released seventh edition of the primary tumor staging system for RCC was a powerful independent predictor of CSS. However, some of the substages identified by the classification had overlapping prognoses, whereas other substages included patients with heterogeneous outcomes. Although in the past few years several reports have highlighted the need to change the TNM classification both for localized and locally advanced stages, only a few modifications have been included in the latest version of the TNM.
Author contributions: Vincenzo Ficarra had full access to all the data in the study and takes responsibility for the integrity of the data and the accuracy of the data analysis.

Study concept and design: Ficarra, Longo, Simonato.

Acquisition of data: Novara, Ficarra, Antonelli, Artibani, Bertini, Carini, Cosciani Cunico, Imbimbo, Longo, Martignoni, Martorana, Minervini, Mirone, Montorsi, Schiavina, Simeone, Serni, Simonato, Siracusano, Volpe, Carmignani.

Analysis and interpretation of data: Novara, Ficarra.

Drafting of the manuscript: Novara, Ficarra.

Critical revision of the manuscript for important intellectual content: Novara, Ficarra, Antonelli, Artibani, Bertini, Carini, Cosciani Cunico, Imbimbo, Longo, Martignoni, Martorana, Minervini, Mirone, Montorsi, Schiavina, Simeone, Serni, Simonato, Siracusano, Volpe, Carmignani. Statistical analysis: Novara.

Obtaining funding: None.

Administrative, technical, or material support: None. Supervision: None.

Other (specify): None.

Financial disclosures: I certify that all conflicts of interest, including specific financial interests and relationships and affiliations relevant to the subject matter or materials discussed in the manuscript (eg, employment/ affiliation, grants or funding, consultancies, honoraria, stock ownership or options, expert testimony, royalties, or patents filed, received, or pending), are the following: None.

Funding/Support and role of the sponsor: The LUNA Foundation received unrestricted grants from Bayer and Pfizer, which made the SATURN project possible. Sponsors had no role in study design, data collection, management, interpretation, analysis, or in manuscript preparation, review, and approval.

\section{Appendix A. Members of the SATURN Project}

European Institute of Oncology, Milan: O. De Cobelli University of Bologna: G. Martorana, R. Schiavina University of Brescia: A. Antonelli, S. Corti, S. Cosciani Cunico, C. Simeone

University of Catania: M. Castelli, S. Cimino, V. Favilla,

G. Morgia

University of Eastern Piedmont, Novara: M. Billia,

C. Terrone, A. Volpe

University Federico II, Naples: C. Imbimbo, N. Longo,

V. Mirone

University of Florence: M. Carini, L. Masieri, A. Minervini,

S. Serni

University of Genova: G. Carmignani, F. Oneto,

A. Simonato, V. Varca

University of Milan: F. Rocco

University of Padua: W. Artibani, V. Ficarra, G. Novara University of Perugia: E. Costantini, M. Porena, A. Zucchi University of Sassari/Messina: G. Morgia

University of Trieste: S. Ciciliato, N. Lampropoulou,

S. Siracusano

University of Turin, Molinette Hospital: D. Fontana,

P. Gontero, A. Tizzani

University of Verona (Pathology): M. Brunelli,

G. Martignoni

University of Verona (Urology): C. Valotto, F. Zattoni 
Vita-Salute University San Raffaele, Milan: R. Bertini, F. Montorsi, G. Petralia, M. Roscigno, E. Strada

\section{References}

[1] Ficarra V, Schips L, Guillè F, et al. Multiinstitutional European validation of the 2002 TNM staging system in conventional and papillary localized renal cell carcinoma. Cancer 2005;104:968-74.

[2] Frank I, Blute ML, Leibovich BC, et al. Independent validation of the 2002 American Joint Committee on cancer primary tumor classification for renal cell carcinoma using a large, single institution cohort. J Urol 2005;173:1889-92.

[3] Bedke J, Pritsch M, Buse S, et al. Prognostic stratification of localized renal cell carcinoma by tumor size. J Urol 2008;180:62-7.

[4] Kinouchi T, Saiki S, Meguro N, et al. Impact of tumor size on the clinical outcomes of patients with Robson stage I renal cell carcinoma. Cancer 1999;689-95.

[5] Lau WK, Cheville JC, Blute ML, Weaver AL, Zincke H. Prognostic features of pathologic stage $\mathrm{T} 1$ renal cell carcinoma after radical nephrectomy. Urology 2002;59:532-7.

[6] Elmore JM, Kadesky KT, Koeneman KS, Sagalowsky AI. Reassessment of the 1997 TNM classification system for renal cell carcinoma. Cancer 2003;98:2329-34.

[7] Igarashi T, Tobe T, Nakatsu HO, et al. The impact of a $4 \mathrm{~cm}$. cutoff point for stratification of T1N0M0 renal cell carcinoma after radical nephrectomy. J Urol 2001;165:1103-6.

[8] Ficarra V, Galfano A, Mancini M, et al. TNM staging system for renalcell carcinoma: current status and future perspectives. Lancet Oncol 2007;8:554-8.

[9] Ficarra V, Guillè F, Schips L, et al. Proposal for revision of the TNM classification system for renal cell carcinoma. Cancer 2005;104: 2116-23.

[10] Frank I, Blute ML, Leibovich BC, et al. pT2 classification for renal cell carcinoma. Can its accuracy be improved? J Urol 2005;173:380-4.

[11] Leibovich BC, Cheville JC, Lohse CM, et al. Cancer specific survival for patients with pT3 renal cell carcinoma-an the 2002 primary tumor classification be improved? J Urol 2005;173:716-9.

[12] Thompson RH, Cheville JC, Lohse CM, et al. Reclassification of patients with pT3 and pT4 renal cell carcinoma improves prognostic accuracy. Cancer 2005;104:53-60.
[13] Ficarra V, Novara G, Iafrate M, et al. Proposal for reclassification of the TNM staging system in patients with locally advanced (pT3-4) renal cell carcinoma according to the cancer-related outcome. Eur Urol 2007;51:722-31.

[14] Ficarra V, Galfano A, Guillé F, et al. A new staging system for locally advanced (pT3-4) renal cell carcinoma: a multicenter European study including 2,000 patients. J Urol 2007;178:418-24.

[15] Margulis V, Tamboli P, Matin SF, et al. Redefining pT3 renal cell carcinoma in the modern era: a proposal for a revision of the current TNM primary tumor classification system. Cancer 2007;109: 2439-44.

[16] Jung SJ, Ro JY, Truong LD, Ayala AG, Shen SS. Reappraisal of T3N0/ NxM0 renal cell carcinoma: significance of extent of fat invasion, renal vein invasion, and adrenal invasion. Hum Pathol 2008;39: 1689-94.

[17] Fujita T, Iwamura M, Yanagisawa N, Muramoto M, Okayasu I, Baba $\mathrm{S}$. Reclassification of the current tumor, node, metastasis staging in pT3 renal cell carcinoma. Int J Urol 2008;15:582-6.

[18] Greene FL, Gospodarowicz M, Wittekend C, et al. American Joint Committee on Cancer (AJCC) staging manual. ed 7. Philadelphia, PA: Springer; 2009.

[19] Patard JJ, Leray E, Cindolo L, et al. Multi-institutional validation of a symptom based classification for renal cell carcinoma. J Urol 2004; 172:858-62.

[20] Kovacs G, Akhtar M, Beckwith BJ, et al. The Heidelberg classification of renal cell tumors. J Pathol 1997;183:131-3.

[21] Fuhrman S, Lasky LC, Limas L. Prognostic significance of morphologic parameters in renal cell carcinoma. Am J Surg Pathol 1982; 6:655-63.

[22] Gospodarowicz MK, Miller D, Groome PA, Greene FL, Logan PA, Sobin LH. The process for continuous improvement of the TNM classification. Cancer 2004;100:1-5.

[23] Ljungberg B, Hanbury DC, Kuczyk MA, et al. Renal cell carcinoma guideline. Eur Urol 2007;51:1502-10.

[24] Novick AC, Campbell SC, Belldegrun A, et al. Guideline for management of the clinical stage 1 renal mass (2009). American Urological Association Web site. http://www.auanet.org/content/ guidelinesand-quality-care/clinical-guidelines/main reports/ renalmass09.pdf. 